\section{Forum: public health observatories and urban health. Introduction}

\author{
Fórum: observatórios de saúde pública \\ e saúde urbana. Introdução
}

\author{
Foro: observatorios de salud pública \\ y salud urbana. Introducción
}

Megumi Kano ${ }^{1}$

system interoperability. Particularly lacking are intra-urban data linking broader determinants of health to health outcomes, broken down by socio-demographic groups and small geographic areas. Even when data are available, the technical capacity for analysis is often limited, and the relationships between the bodies producing the evidence and those that should consider them for their policy making are weak or do not exist. As a result, urban health equity problems often go unrecognized, at least officially, and urban policies are guided and resourced based on insufficient or inappropriate information.

In a pursuit of possible solutions to this structural deficiency, the World Health Organization (WHO) Centre for Health Development in Kobe, Japan, cast its attention to local public health observatories around the world, serving urban populations $3,4,5$. Several of them had made significant achievements in developing locally relevant public health knowledge, and influencing urban health and development policies through an approach that engaged multiple sectors of both government and society. One of the keys to their success is to be flexible and responsive to their unique local context. They are not one-size-fits-all. There are, however, valuable insights and learning opportunities to be gained from local public health observatories at all levels of development, from those in inception, to those in maturation, or even going through "retirement". 
This Forum presents the experiences and perspectives of local public health observatories in various stages of development, each from a different country. First, Carlos Castillo-Salgado introduces a recently established public health observatory at the Johns Hopkins University Bloomberg School of Public Health in Baltimore, USA. It integrates an academic training and research programme for public health professionals with the functions of an urban-focused public health observatory. Next, Maria Angelica Salles Dias and colleagues describe the international and local influences which contributed to the establishment of the Belo Horizonte Observatory for Urban Health in Brazil. They explain how the observatory matured over the following 12 years, and what opportunities and challenges it faces today. Finally, John Wilkinson, Director of the former North East of England Public Health Observatory (now part of Public Health England's Knowledge and Intelligence Team), retraces the development trajectory of local public health observatories in England, which included the London Health Observatory among many others. He concludes by discussing the different facets of ensuring the legacy of those observatories in a changing national environment. Together the articles in this Forum portray the different ways in which local public health observatories can be created and evolve, while being similar in their aim to generate detailed information at the local level about the causes of ill health and the systematic differences between people and places, as well as their potential remedies.

Every member of an urban community, from the local municipal government to local businesses, civil society organizations or individual citizens, can and should benefit from well-informed policy making and resource allocation. Cities must develop and strengthen structural capacities that will enable them to understand their current state, anticipate future trends, and translate them into appropriate equity-oriented strategies and policies. Cities need to be capable of accomplishing this in a timely and comprehensive manner if they are to be prosperous cities which ensure quality of life, equity and environmental sustainability in a rapidly and constantly changing world. Local public health observatories can play a pivotal role in making this a reality.

\section{References}

1. World Health Organization. Urbanization and health. Bull World Health Organ 2010; 88:245-6.

2. United Nations Human Settlements Programme. State of the world's cities 2012/13: prosperity of cities. http://mirror.unhabitat.org/pmss/listItemDetails.aspx?publicationID=3387 (accessed on 19/ Mar/2015).

3. WHO Centre for Health Development. Urban health observatories: a possible solution to filling a gap in public health intelligence. http://www.who. int/kobe_centre/publications/uho_policybrief/ en/ (accessed on 19/Mar/2015).
4. Caiaffa WT, Friche AA, Dias MA, Meireles AL, Ignacio CF, Prasad A, et al. Developing a conceptual framework of urban health observatories toward integrating research and evidence into urban policy for health and health equity. J Urban Health 2014; 91:1-16.

5. WHO Centre for Health Development. Providing health intelligence to meet local needs: a practical guide to serving local and urban communities through public health observatories. http://www. who.int/iris/handle/10665/152645\#sthash.7jXmD k7T.dpuf (accessed on 19/Mar/2015).

Submitted on 26/Mar/2015

Approved on 13/Apr/2015 